Check for updates

Cite this: RSC Adv., 2019, 9, 39622

Received 8th October 2019

Accepted 25th November 2019

DOI: 10.1039/c9ra08152f

rsc.li/rsc-advances

\section{Dendritic fibrous nano-silica \& titania (DFNST) spheres as novel cataluminescence sensing materials for the detection of diethyl ether $\uparrow$}

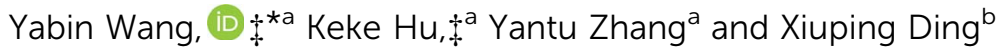

Selective and controllable cataluminescence (CTL) sensors for volatile organic compounds (VOCs) are significant for chemical safety, environmental monitoring, health effects on human beings, and so forth. Most of the exploited CTL-based sensors suffer relatively low response and poor selectivity because of their high sensitivities to interferential substances. In this investigation, dendritic fibrous nano-silica \& titania (DFNST) spheres have been synthesized as novel sensing materials and the corresponding DFNSTbased CTL sensor has been fabricated to detect diethyl ether with high selectivity via a method of utilizing one $440 \mathrm{~nm}$ bandpass filter. The as-prepared DFNST hybrids not only keep the excellent dendritic fibrous morphology but also bear ca. 21 wt\% catalytic titanium oxide of anatase crystalline structure. The DFNST-based sensor exhibits extremely strong CTL emission at $440 \mathrm{~nm}$ toward diethyl ether against other VOCs like acetone, ethyl acetate, butanol, and so forth. The high response can be attributed to the unique architectural texture of DFNST. Under the optimum parameters, ether could be easily detected in a wide range from 2.0 to $40.0 \mathrm{mM}$ with a fine detection limit of $1.55 \mathrm{mM}(\mathrm{S} / \mathrm{N}=3)$. Furthermore, the working life of this CTL sensor is satisfactory with outstanding stability and durability, far from damaging the morphology and activity of the DFNST sensing material. In conclusion, it is expected that this novel sensing material, the relevant CTL sensor, and the approach of employing the bandpass filter will be significant for the detection of diethyl ether in actual applications.
\end{abstract}

\section{Introduction}

Detrimental volatile organic compounds (VOCs) can lead to short- or long-term potential health effects on human beings. In the past few decades, multitudinous measuring techniques were explored to detect and discriminate hazardous chemicals in VOCs, such as inductively coupled plasma mass spectrometry (ICP-MS), gas chromatography mass spectrometry (GC-MS), and gas sensors. ${ }^{1-6}$ Among these techniques, gas sensors are deemed to be promising because of their high sensitivity, longterm stability, and the simplicity of the apparatus. Cataluminescence (CTL)-based sensors, as one type of gas sensors, possess further excellent detection advantages of rapid response, high signal/noise ratio $(\mathrm{S} / \mathrm{N})$, stable and durable intensity, etc. ${ }^{2,3,7}$ In short, CTL-based sensors provide a versatile path for VOCs differentiation.

\footnotetext{
${ }^{a}$ Shaanxi Key Laboratory of Chemical Reaction Engineering, College of Chemistry and Chemical Engineering, Yan'an University, Yan'an 716000, Shaanxi, P. R. China. E-mail: ybw_bingerbingo@126.com

${ }^{b}$ Key Laboratory of Comprehensive and Highly Efficient Utilization of Salt Lake Resources, Salt Lake Chemistry Analysis and Test Center, Qinghai Institute of Salt Lakes, Chinese Academy of Sciences, Xining 810008, P. R. China

$\dagger$ Electronic supplementary information (ESI) available. See DOI: 10.1039/c9ra08152f \$ These authors contributed equally to this work.
}

Diethyl ether as one of the harmful VOCs has posed a threat on human health and environmental security, owing to its flammable and explosive characters. As a consequence, it is imperative to detect diethyl ether in medicine, laboratory or industry applications. Considerable advances have been made in CTL-based sensors for diethyl ether detection, especially the utilized sensing materials. For example, Li's team fabricated core-shell $\mathrm{Fe}_{3} \mathrm{O}_{4} @ \mathrm{SiO}_{2}$ microspheres and applied them to detect diethyl ether. ${ }^{8}$ Under the optimal conditions, the system could achieve a detection range of 10-3000 ppm and own the detection limit of about 6.7 ppm. Lu et al. employed mesoporous $\mathrm{TiO}_{2}$ nanoparticles as the catalytic material and solely diethyl ether displayed strong CTL emission at $440 \mathrm{~nm}$ in a range of 2.0 to $50.0 \mathrm{mM}^{2}$ Very recently, Zhen and coworkers used $\alpha-\mathrm{MoO}_{3}$ nanobelts as the sensing material for ether detection. The $\alpha-\mathrm{MoO}_{3}$ sensor brought about a lower detection temperature at $120{ }^{\circ} \mathrm{C}$ with a wide detection range of 9-2000 ppm and a low detection limit of about 7.5 ppm. ${ }^{9}$ From the above investigations, it can be concluded that nanomaterials have unique advantages as the sensing materials to fabricate CTL sensors because of their unique structural characteristics, like large surface areas and numerous active sites.

As introduced and classified in our previous work, ${ }^{10}$ dendritic fibrous nano-particles (DFNPs) possess threedimensional (3D) center-radial nanochannels along with 
hierarchical nanopores (Fig. 1a) that give rise to larger pore volume and specific surface area, compared with most of traditional mesoporous materials like MCM-41 and SBA-15. DFNPs family can be divided into the pure ones (silica-, carbon-, titania-, etc.) and the hybrid like nano-silica \& titania. However, up to now, only silica-based DFNPs (dendritic fibrous nano-silica, DFNS $)^{\mathbf{1 0}-\mathbf{1 6}}$ have drawn considerable attention and undergone speedy development. It is worth to mention that DFNS was originally denominated and well-known as KCC1. ${ }^{17-26}$ As DFNS subject boomingly developed, the idea of preparing dendritic fibrous nano-silica \& titania (DFNST) naturally showed up, owing to the particular optical and electronic properties of titania $\left(\mathrm{TiO}_{2}\right)$. Our team and some other groups have proposed to manufacture DFNST hybrid with DFNS as hard template by the post-grafting method. ${ }^{\mathbf{1 0 , 2 7 - 2 9}}$

In this work, we first prepared DFNST nanospheres by grafting TBOT onto DFNS surfaces as demonstrated in Fig. 1b. The asprepared products not only keep the excellent dendritic fibrous topology but also bear $c a .21 \mathrm{wt} \%$ titanium oxide of anatase crystalline structure. The architecture and fundamental physicochemical properties were probed into by SEM, TEM, X-ray diffraction (XRD), X-ray photoelectron spectroscopy (XPS), inductively coupled plasma optical emission spectrometry (ICP-OES), $\mathrm{N}_{2}$ adsorption-desorption isotherms, Fourier transform infrared spectroscopy (FT-IR), and Raman spectrum. Secondly, for the first time, the as-prepared DFNST photocatalysts were pioneeringly applied as the sensing materials for the detection of diethyl ether via CTL (Fig. 1c). Highly selective detection was controllable and realized by locating the detection position at $440 \mathrm{~nm}$ via one wavelength bandpass filter. Under the optimal parameters, DFNSTbased sensor could identify diethyl ether in a range of $2.0-40.0 \mathrm{mM}$ with a detection limit of $1.55 \mathrm{mM}(\mathrm{S} / \mathrm{N}=3)$. Finally, the plausible CTL mechanism was proposed and discussed.

\section{Experimental details}

\section{Chemicals}

Tetraethylorthosilicate (TEOS), tetrabutyl orthotitanate (TBOT), cetylpyridinium bromide (CPB), ammonium hydroxide $\left(\mathrm{NH}_{3} \cdot \mathrm{H}_{2} \mathrm{O}\right)$, urea, cyclohexane, pentanol, ethyl alcohol, and diethyl ether were purchased from Aladdin Corporation.

\section{Synthesis processes}

DFNS synthesis. DFNS was fabricated by a one-pot rotating hydrothermal technique via a JX-8-200 homogeneous reactor (China) with a certain stirring rate as reported in our previous work. ${ }^{10,30}$ Tetraethyl orthosilicate (TEOS, $2.5 \mathrm{~g}, 0.012 \mathrm{~mol}$ ) was dissolved in a mixed cyclohexane $(30 \mathrm{~mL})$ and pentanol (1.5 $\mathrm{mL})$. Another solution of urea $(0.6 \mathrm{~g}, 0.01 \mathrm{~mol})$ and cetylpyridinium bromide (CPB, $1 \mathrm{~g}, 0.0026 \mathrm{~mol})$ in water $(30 \mathrm{~g}, 1.67 \mathrm{~mol})$ was poured into the above organic solution. The mixture solution was stirred for $60 \mathrm{~min}$ at $25{ }^{\circ} \mathrm{C}$ and then placed in an autoclave. Then, the autoclave was heated at $120{ }^{\circ} \mathrm{C}$ for $4 \mathrm{~h}$ with a stirring rate of 60 revolutions per minute (rpm). Finally, the product was centrifugated, washed with acetone for six times, and calcined at $550{ }^{\circ} \mathrm{C}$ for $6 \mathrm{~h}$, respectively.

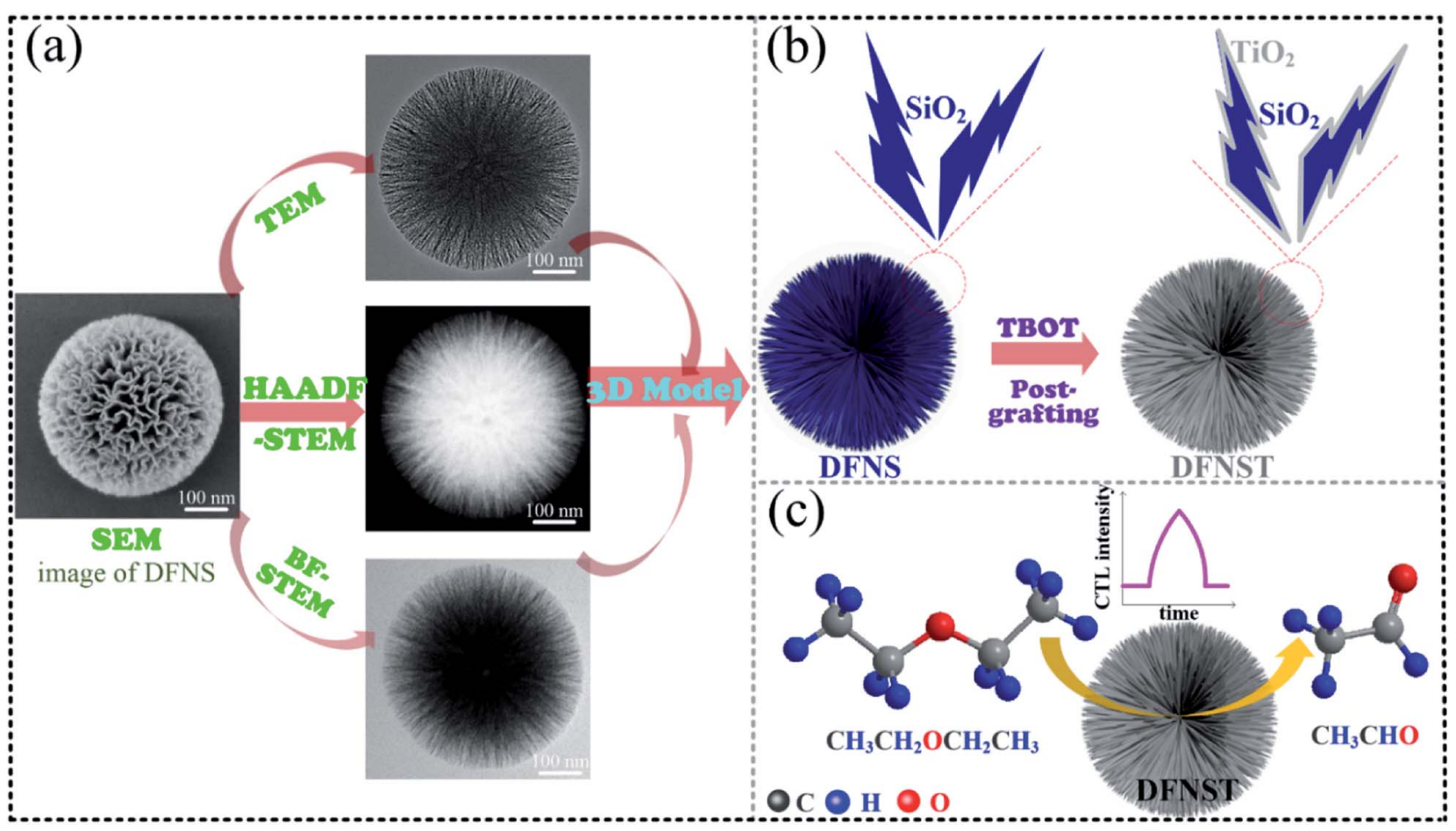

Fig. 1 (a) SEM, TEM, high-angle annular dark field STEM (HAADF-STEM), bright field STEM (BF-STEM) of a DFNS individual. (b) The 3D model of

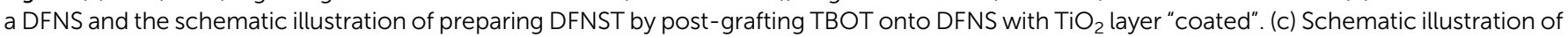
DFNST-based CTL sensing material for the detection of diethyl ether. 
DFNST synthesis. DFNST was synthesized by the postgrafting approach with some modifications, on the basis of the ammonia-assisted solution-phase deposition technique. ${ }^{27}$ In a typical synthesis, DFNS (0.5 g) and anhydrous ethanol (100 $\mathrm{mL}$ ) were placed in a round-bottomed flask with sufficient mixture (sonication for $30 \mathrm{~min}$ and stirring for $10 \mathrm{~min}$ ). To the stirring solution, aqueous ammonia $(1 \mathrm{~mL}, 25 \%)$ in $5 \mathrm{~mL}$ anhydrous ethanol was added dropwise over $10 \mathrm{~min}$. After that, $2.5 \mathrm{~mL}$ TBOT with different amount in $5 \mathrm{~mL}$ anhydrous ethanol was then added dropwise at a speed of one liquid drop per ten seconds at RT. Then, the flask was connected to the vacuum system with sonication at $0{ }^{\circ} \mathrm{C}$ for $4 \mathrm{~h}$. The reaction temperature was then boosted to $45{ }^{\circ} \mathrm{C}$ and kept for $20 \mathrm{~h}$ under continuous stirring. The resultant product was isolated by centrifugation, washed with abundant ethanol thrice, dried at $55^{\circ} \mathrm{C}$ in an oven, and finally calcined at $750{ }^{\circ} \mathrm{C}$ for $5 \mathrm{~h}$ in air by a muffle furnace. In addition, the as-prepared pristine DFNST samples without post-calcination treatment are denoted as DFNST-ASP.

\section{Characterization}

Structural and physicochemical properties. Scanning electron microscopy (SEM) was carried out with a HITACHI-SU8010 field emission (Japan). Transmission electron microscopy (TEM) was conducted by a JEM-F200 (Japan) to obtain bright field (BF-STEM), high-angle annular dark field (HAADF-STEM), high resolution transmission electron microscopy (HRTEM), selected area electron diffraction (SAED), and TEM-mapping. $\mathrm{X}$ ray diffraction (XRD) patterns were redorded on a PANalytical $\mathrm{X}^{\prime}$ Pert Pro X-ray diffractometer (Netherlands) with $\mathrm{Cu} \mathrm{K} \alpha$ radiation. An autosorb-iQ ${ }_{2}$-MP analyzer (USA) was employed to measure $\mathrm{N}_{2}$ adsorption-desorption isotherms, and the data were dealt with BET analysis. A NEXUS-870 infrared spectrometer (USA) was utilized to record Fourier transform infrared spectroscopy (FT-IR). Raman spectra were recorded by a HORIBA LabRAM HR evolution with excitation at $\lambda=532 \mathrm{~nm}$ and an integration time of $100 \mathrm{~s}$ (France). XPS were performed on an ESCALAB 250Xi with $\mathrm{Al} \mathrm{K} \alpha$ radiation (Thermo Fisher Scientific) and the binding energy scale was calibrated by hydrocarbon contamination with $\mathrm{C} 1 \mathrm{~s}$ at $284.8 \mathrm{eV}$. The titanium content and silicon content were analyzed using a PerkinElmer 5300 ICP-OES instrument (PerkinElmer, USA), where each sample was predigested with a Milestone Ethos-1 microwave digester prior to measurement. The ultraviolet visible diffuse reflectance spectroscopy (UV-Vis-DRS) were measured with a UV-2550 UV-Vis spectrophotometer (Shimadzu, Japan).

CTL measurement. Diethyl ether was measured by an ultraweak luminescence analyzer via the DFNST-based CTL sensor. In general, $100 \mathrm{mg}$ DFNST were uniformly coated on a cylindrical ceramic heater with the inner diameter of $0.5 \mathrm{~cm}$ and the length of $5.0 \mathrm{~cm}$, which was inserted into the quartz tube with a diameter of $1.0 \mathrm{~cm}$ and a length of $7.0 \mathrm{~cm}$. The operating temperature of 200 to $360{ }^{\circ} \mathrm{C}$ was controlled by a voltage controller. The flow rate was adjusted from 90 to $210 \mathrm{~mL} \mathrm{~min}{ }^{-1}$ by a precision flow meter. Different amount of diethyl ether gas of $5 \mathrm{~mL}(1 \mathrm{mM}$ to $50 \mathrm{mM})$ was pumped into gasification chamber. The data integration time was set at one second per count $(1.0 \mathrm{~s})$, and the detection limit was confirmed by the integration time of $0.5 \mathrm{~s}$ as well.

\section{Results and discussion}

\section{SEM and TEM analysis}

Fig. 2a displays SEM images of DFNS nanospheres with different magnifications. In order to observe the grafting process of TBOT onto DFNS, DFNST without calcination treatment (DFNST-ASP) were detected by SEM as shown in Fig. 2b. Even though TBOT precursor molecules hydrolyze to the sol-gel intermediate (mainly containing Ti-OH), the resultant products are still monodisperse without agglomeration and their surfaces keep smooth as well. Moreover, the nanopores are filled and packed obviously. The morphologies of these nanospheres greatly alter and the surfaces become rough upon calcining at $750{ }^{\circ} \mathrm{C}$ as exhibited in Fig. 2c. Spherical architectures are well preserved only with nanopores packed and decrescent. DFNS and DFNST samples with different $\mathrm{TiO}_{2}$ loading were characterized by the ICP-OES technique and the results are summarized in Table 1. Fig. 2d displays TEM images of DFNS nanospheres with different magnifications. It is apparent that DFNS spheres possess the dendrimer-like structures with unique center-radial fibrous nanochannels. Fig. 2e shows TEM images of DFNST prepared by the post-grafting approach with calcination treatment. The dendritic structure becomes ambiguous and the center-radial state insensibly grades into solid shape from the outer to the inside. The nanochannels are filled with $\mathrm{TiO}_{2}$ and become hard to be observed. The results confirm that $2.5 \mathrm{~mL}$ TBOT with Ti/Si molar ratio of 0.27 could be the ideal amount for DFNST of distinct dendritic fibrous morphology, in good agreement with SEM results.

Up to now, it is quite clear that DFNST can not only reserve representative dendritic fibrous architecture, but also load the sufficient $\mathrm{TiO}_{2}$ without destroying the dendritic fibrous morphology. Therefore, the sample was further explored by HRTEM (Fig. 2f-h) and SAED (Fig. 2i). HR-TEM images manifest that some $\mathrm{TiO}_{2}$ particles of $c a .10 \mathrm{~nm}$ disperse in DFNST channels (red circle). This observation demonstrates that part TBOT sol-gel coated on DFNS surface (Fig. 2b) thermally transforms into $\mathrm{TiO}_{2}$ nanoparticles (Fig. 2f-h) under calcination procedure. As a consequence, smooth surfaces of DFNST-ASP without calcination (Fig. 2b, sol-gel) become rough (Fig. 2c, nanoparticles) after being heated at elevated temperature. The interplanar distances ( $d$-spacings) of $0.35 \mathrm{~nm}$ from HR-TEM in Fig. $2 \mathrm{~h}$ and the crystal planes of (101), (103), (200), (105), (213) from the SAED in Fig. $2 \mathrm{i}$ preliminary prove that the as-obtained $\mathrm{TiO}_{2}$ is anatase with poly-crystal structure.

\section{XRD, FT-IR, Raman, XPS, and $\mathbf{N}_{2}$ adsorption-desorption isotherms analyses}

Fig. 3a shows XRD patterns of DFNS and DFNST specimens. Broad peak located at $22^{\circ}$ between $15^{\circ}$ and $30^{\circ}$ corresponds to amorphous silica for DFNS. ${ }^{\mathbf{2 4 , 3 1 , 3 2}}$ As for DFNST, this peak sharply lessened and characteristic peaks of anatase $\mathrm{TiO}_{2}$ show up including (101), (004), (200), (211), and (204). Combined with 

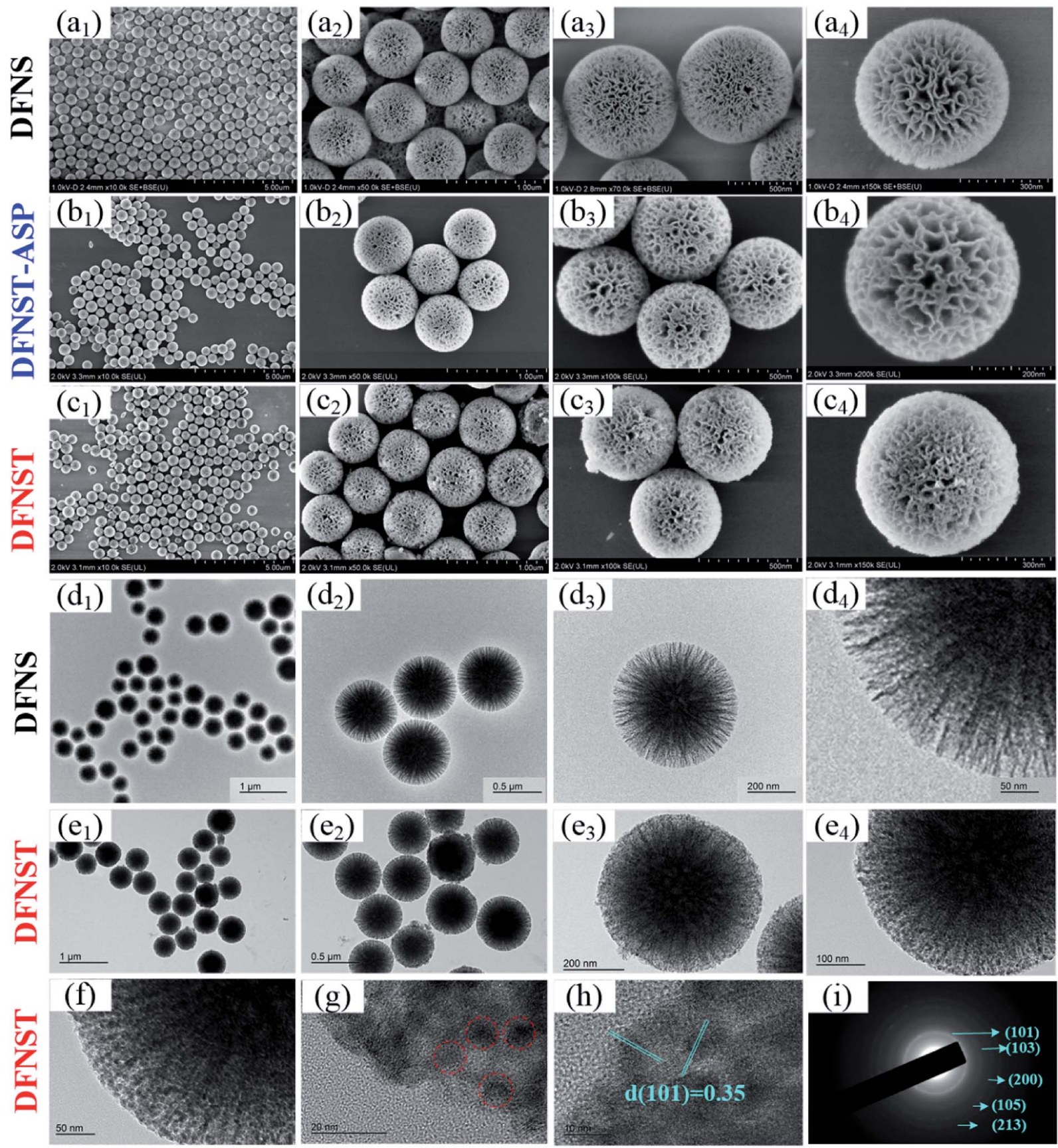

Fig. 2 SEM images of DFNS $\left(a_{1}-a_{4}\right)$, DFNST without calcination treatment (DFNST-ASP, $b_{1}-b_{4}$ ), and DFNST with calcination treatment (DFNST, $\left.c_{1}-c_{4}\right)$ under different magnifications. TEM images of DFNS $\left(d_{1}-d_{4}\right)$ and DFNST $\left(e_{1}-e_{4}\right)$ under different magnifications. HR-TEM images of DFNST under different magnifications ( $f-h)$ and the corresponding SAED result (i).

HR-TEM (Fig. 2f-h) and SAED (Fig. 2i) results, $\mathrm{TiO}_{2}$ in DFNST can be fully confirmed to be anatase structure.

FT-IR spectrograms of DFNS and the as-prepared DFNST are exhibited in Fig. 3b. For DFNS reference, $1645 \mathrm{~cm}^{-1}, 1090 \mathrm{~cm}^{-1}$, $963 \mathrm{~cm}^{-1}$, and $810 \mathrm{~cm}^{-1}$ can be ascribed to $\mathrm{Si}-\mathrm{O}-\mathrm{Si}$, and $\mathrm{H}_{2} \mathrm{O},{ }^{32}$ vibration absorptions of $\mathrm{Si}-\mathrm{OH},{ }^{31}$ symmetrical stretching vibration of $\mathrm{Si}-\mathrm{O},{ }^{33}$ respectively. The adsorbed $\mathrm{H}_{2} \mathrm{O}$ and $\mathrm{Si}-\mathrm{OH}$ groups on the surfaces lead to the typical absorption of $-\mathrm{OH}$ group at $3430 \mathrm{~cm}^{-1}$. As for DFNST, characteristic peaks of DFNS dwindle, indicating that these functional groups are covered by
$\mathrm{TiO}_{2}$ products or interact with TBOT. Characteristic flat broad peaks centered at 530 to $630 \mathrm{~cm}^{-1}$ ascribe to vibration absorptions of $\mathrm{Ti}-\mathrm{O}-\mathrm{Ti}^{34-36}$ The above results imply that Ti-OH groups originated from hydrolyzed TBOT condense with one another at the elevated temperature to generate Ti-O-Ti. More importantly, the peaks at about $960 \mathrm{~cm}^{-1}$ that overlap with $\mathrm{Si}-\mathrm{OH}$ and correspond to $\mathrm{Si}-\mathrm{O}-\mathrm{Ti}^{36,37}$ become easy to be observed from DFNS to DFNST, revealing that Ti-OH groups derived from hydrolyzed TBOT undergo hetero-condensation chemical reaction with $\mathrm{Si}-\mathrm{OH}$ groups on DFNS substrates to produce $\mathrm{Si}-\mathrm{O}-\mathrm{Ti}$ 
Table 1 Chemical and textural properties of DFNS and DFNST

\begin{tabular}{llllll}
\hline Sample & TBOT volume $(\mathrm{mL})$ & $\mathrm{TiO}_{2}{ }^{a}(\mathrm{wt} \%)$ & $\mathrm{SiO}_{2}{ }^{a}(\mathrm{wt} \%)$ & $\mathrm{Ti} / \mathrm{Si}{ }^{b}($ molar ratio $)$ & $S_{\mathrm{BET}}\left(\mathrm{m}^{2} \mathrm{~g}^{-1}\right)$ \\
\hline DFNS & 0 & 0 & 80.27 & 0 & 421.374 \\
DFNST & 2.5 & 21.44 & 60.42 & 0.27 & 310.514
\end{tabular}

${ }^{a}$ Measured by ICP-OES analysis. ${ }^{b}$ Calculated by ICP-OES result; $S_{\mathrm{BET}}$ stands for BET surface area; $V_{\mathrm{P}}$ is pore volume.

cross-linked structures. Raman tests of the as-prepared DFNST are also conducted to further ascertain $\mathrm{TiO}_{2}$ crystal structure (Fig. 3c). Typical anatase peaks of $\mathrm{E}_{\mathrm{g}}, \mathrm{B}_{1 \mathrm{~g}}$, and $\mathrm{A}_{1 \mathrm{~g}}+\mathrm{B}_{1 \mathrm{~g}}$ are detected and located at around $140(630), 380$, and $500 \mathrm{~cm}^{-1}$, respectively. ${ }^{\mathbf{3 8 - 4 0}}$

The prominently intense low frequency mode at $140 \mathrm{~cm}^{-1}$ can be attributed to $\mathrm{O}-\mathrm{Ti}-\mathrm{O}$ bending vibration within coordinated $\mathrm{TiO}_{2}$ octahedra. XPS survey spectra of DFNST (Fig. 3d) reveals that $\mathrm{Si} 2 \mathrm{p}, \mathrm{O} 1 \mathrm{~s}$, and $\mathrm{Ti} 2 \mathrm{p}$ collectively exist on its surface, except for $\mathrm{C}$ 1s contamination. The corresponding highresolution XPS spectra of Si 2p, O 1s, and Ti 2p are presented in Fig. 3e-g. De-convolution of $\mathrm{O} 1 \mathrm{~s}$ produces three peaks and can be ascribed to Ti-O-Ti at $530.32 \mathrm{eV}, \mathrm{Si}-\mathrm{O}-\mathrm{Ti}$ at $532.49 \mathrm{eV}$, and $\mathrm{Si}-\mathrm{O}-\mathrm{Si}$ at $533.62 \mathrm{eV}$, respectively. ${ }^{\mathbf{4 1 , 4 2}}$ This result coincides with the previously reported one that hetero-condensation of Si-O-Ti takes place during DFNST formation. ${ }^{43}$ Ti $2 \mathrm{p}$ XPS (a)

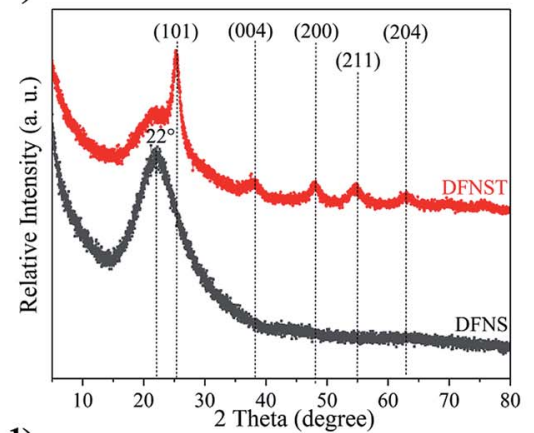

(d)

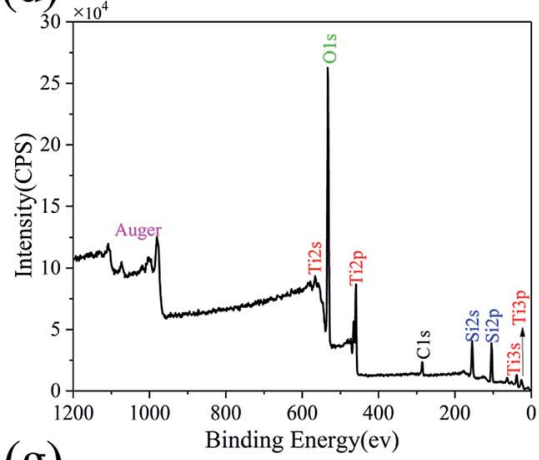

(g)

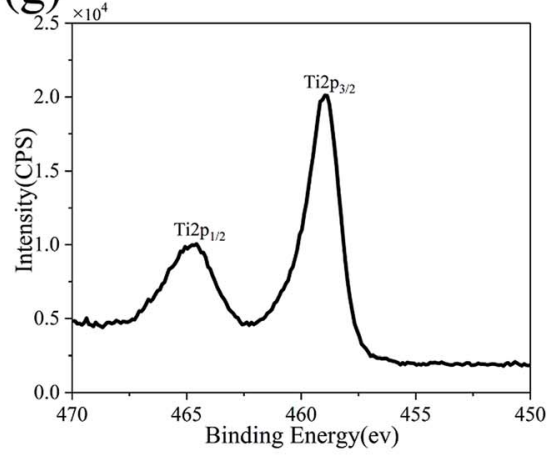

(b)

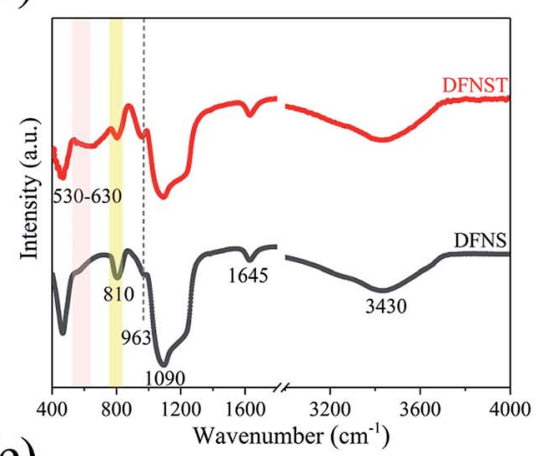

(e)

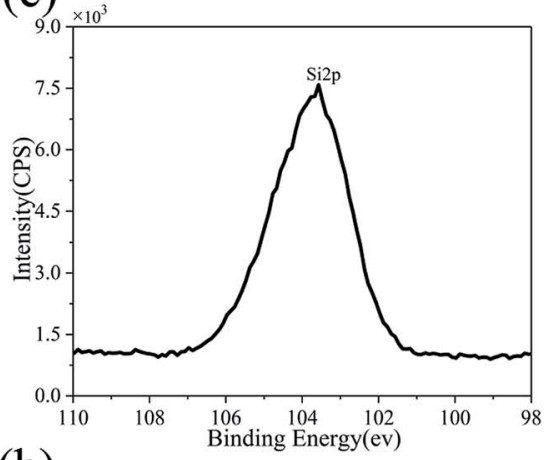

(h)

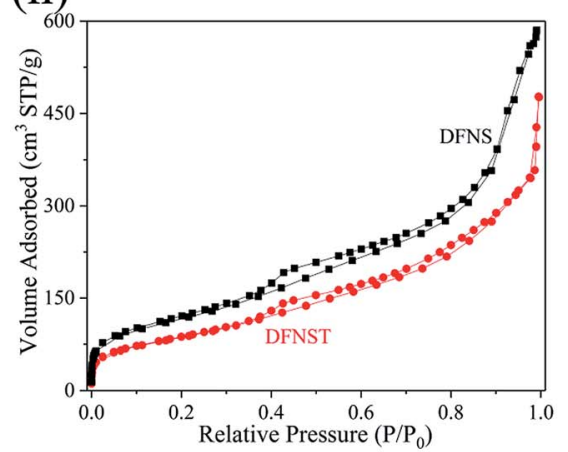

(c)

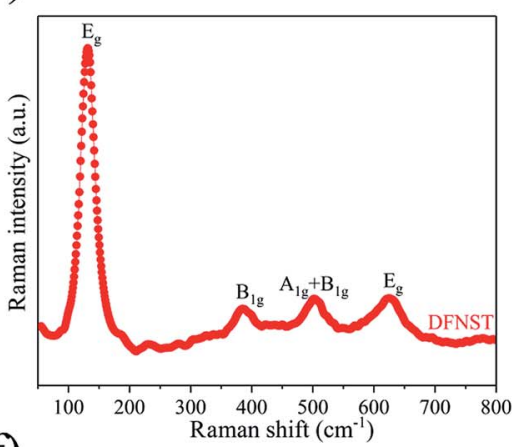

(f)

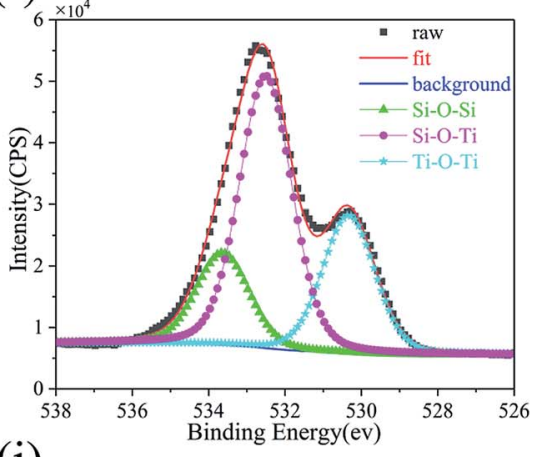

(i)

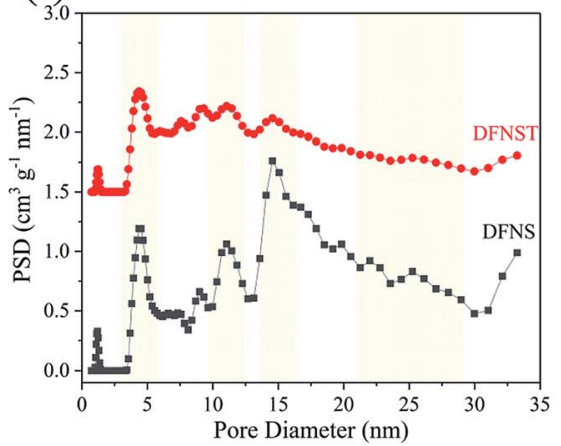

Fig. 3 XRD (a) and FT-IR (b) of DFNS and DFNST. Raman (c), XPS survey scan (d), and high-resolution XPS spectra (e-g) curves of DFNST. N2 adsorption-desorption isotherms ( $h$ ) and the corresponding pore size distributions (i) of DFNS and DFNST. 
spectra demonstrates the typical doublet peaks of $\mathrm{Ti} 2 \mathrm{p}_{3 / 2}$ at $458.97 \mathrm{eV}$ and $\mathrm{Ti} 2 \mathrm{p}_{1 / 2}$ at $464.57 \mathrm{eV}^{42}$ The $\mathrm{N}_{2}$ adsorptiondesorption isotherms and the corresponding pore size distributions of DFNS and the as-prepared DFNST are shown in Fig. $3 \mathrm{~h}$ and i, respectively. All samples have similar IV characters of typical $\mathrm{H}_{3}$ hysteresis loops in their isotherms. It is well-known that type $\mathrm{H}_{3}$ loop usually appears with aggregates of plate-like particles that evolve into slit-shaped pores, ${ }^{\mathbf{4 4}}$ here in correspondence with the nanochannels of the bulks. The pore size of DFNS exhibits four evident wide distributions at $c a .4,11,15$, and $25 \mathrm{~nm}$, which could be various nanopores in DFNS as verified by SEM, TEM, and our previous reports. ${ }^{30}$ For DFNST sample, the peaks become weaker and even vanish. The corresponding pore volume $\left(V_{\mathrm{P}}\right)$ and BET surface area $\left(S_{\mathrm{BET}}\right)$ are listed in Table 1. DFNS nanospheres synthesized without TBOT have the maximum $S_{\mathrm{BET}}$ and $V_{\mathrm{P}} . S_{\mathrm{BET}}$ and $V_{\mathrm{P}}$ greatly decrease as TBOT was added, nearly three fourths of DFNS reference. Based on the above SEM, TEM, ICP-OES, and $\mathrm{N}_{2}$ adsorption-desorption results, it can be concluded that DFNST could be the ideal target products which load sufficient anatase $\mathrm{TiO}_{2}$ without damaging the particular dendritic fibrous textures.

\section{Optimization of CTL conditions and the sensor's stability}

To gain the optimal working parameters (conditions) for the detection of ether, optimization processes for excellent CTL ability of DFNST were performed where the wavelength of CTL emission, the working temperature, and the flow rate of gas carrier were successively probed into (Fig. 4a-c). Eight wavelengths of CTL emission were investigated as displayed in Fig. 4a and $\mathrm{S} 1 \dagger$ (the original data), including 400, 425, 440, 460, 490, 555, 575 and $620 \mathrm{~nm}$. It can be clearly seen that CTL intensity boosts with the increase of filter wavelength below $440 \mathrm{~nm}$ and decreases sharply above $440 \mathrm{~nm}$. The maximal CTL intensity locates at $440 \mathrm{~nm}$ which was selected as the optimal detection wavelength for the subsequent studies. To our excitement, nearly all noise signal can be eliminated with the bandpass filter at $440 \mathrm{~nm}$, as verified in Fig. S2. $\dagger$ In addition, the CTL intensity is very strong under this situation with the value of about $2 \times 10^{5}$ count. Hence, the bandpass filter at $440 \mathrm{~nm}$ was utilized throughout the following experiments without discussing the signal/noise $(\mathrm{S} / \mathrm{N})$ ratio. $^{2} \mathrm{CTL}$ intensity of DFNST towards working temperatures were measured and the results were demonstrated in Fig. $4 \mathrm{~b}$ and $\mathrm{S} 3 \uparrow$ (the original data). On the whole, the intensity increases monotonically from 200 to $360{ }^{\circ} \mathrm{C}$. When the working temperatures is less than $240{ }^{\circ} \mathrm{C}$, the corresponding CTL intensity is very weak. When the working temperatures outweigh $260{ }^{\circ} \mathrm{C}$, the corresponding CTL intensity greatly increase with a gradient of $K$. However, the increase trend decreases as the working temperatures reaches $300{ }^{\circ} \mathrm{C}$ with a gradient of $K^{\prime}$. Therefore, $280{ }^{\circ} \mathrm{C}$ was considered as the optimal detection temperature for the subsequent researches $\left(K^{\prime}<K\right)$. Fig. 4c and $\mathrm{S} 4 \uparrow$ (the original data) illustrate the CTL intensity at different rate of 90 to $300 \mathrm{~mL} \mathrm{m^{-1 }}$ under the optimized working temperature of $280{ }^{\circ} \mathrm{C}$ and the wavelength of $440 \mathrm{~nm}$. It is clear that the maximal CTL intensity locates at 210 $\mathrm{mL} \min ^{-1}$ which was selected as the optimal rate for the subsequent studies. The CTL intensity begins to decrease as the flow rate is greater than $210 \mathrm{~mL} \mathrm{~min}^{-1}$, which might be aroused by insufficient reaction time between DFNST and ether. Under the optimum experimental conditions $\left(440 \mathrm{~nm}, 280{ }^{\circ} \mathrm{C}\right.$, and 210 $\mathrm{mL} \min ^{-1}$ ), the curve of CTL intensity versus diethyl ether concentration was plotted as shown in Fig. $4 \mathrm{~d}$ and S5. $\dagger$ The intensity is proportional to the concentration in a range of 2.0 to $40 \mathrm{mM}$ (Fig. 4e). The liner equation can be $y=10183 x-25288$ with $R^{2}$ of 0.9963 , where $y$ and $x$ are CTL intensity and ether concentration, respectively. The detection limit of diethyl ether $(\mathrm{S} / \mathrm{N} \approx 3)$ is $1.55 \mathrm{mM}$ which was validated both in the data integration time of $1.0 \mathrm{~s}$ and $0.5 \mathrm{~s}$, as exhibited in Fig. $4 \mathrm{f}$. The stability of the as-prepared DFNST-based sensor was conducted by persistently injecting $20 \mathrm{mM}$ ether for seven rounds. The relative standard deviation (RSD) was $2.47 \%$, indicative of the sensor's highly stability (Fig. 4g). The as-prepared DFNST-based sensor suffered about 200 tests under different experiment conditions for the optimization of CTL conditions, the exploration of CTL intensity versus diethyl ether concentration as well as the detection limit, RSD determination, and VOCs selectivity (displayed later). The color of the fresh DFNST without any test as the sensing material is white and becomes yellow after all these tests (Fig. 4h). However, the chemical composition of the utilized DFNST remains unchanged as indicated by XRD result in Fig. S7. $\dagger$ SEM images of the final products were also characterized as photographed in Fig. 4i. It is clear to be observed that the morphology and the structure of the final DFNST are highly identical with the pristine ones (Fig. 2c), revealing the outstanding stability of this sensing material.

\section{The selectivity of DFNST-based CTL sensor and the plausible mechanism}

The CTL spectra of different VOCs (herein, including ether, acetone, ethyl acetate, butanol, ethyl alcohol, acetaldehyde, formaldehyde, methanol, and acetic acid) were measured using the DFNST-based sensor without or with the bandpass filter at $440 \mathrm{~nm}$. As shown in Fig. 5a and S6, $\uparrow$ diethyl ether, acetone, ethyl acetate, and butanol exhibit CTL signals of different relative intensities without the $440 \mathrm{~nm}$ bandpass filter, revealing that diethyl ether cannot be discriminated over these VOCs under this circumstance. Oppositely, CTL signals of diethyl ether, acetone, ethyl acetate, and butanol are largely prevented with the bandpass filter. Nevertheless, ether shows an apparent CTL signal than the other three. The selective detection of ether could be realized easily, proving that the DFNST-based sensor is sensitive and effective. It is well-known that the high selectivity can be primarily ascribed to the various VOCs reaction intermediates. Previous investigations have testified that the emitter from ether- $\mathrm{TiO}_{2} \mathrm{CTL}$ sensors was excited-state $\mathrm{CH}_{3} \mathrm{CHO}^{*}$. Diethyl ether transformed into $\mathrm{CO}_{2}$ byproducts and acetaldehyde in the end., ${ }^{2,9}$ BTB indicator and the saturated $\mathrm{Ca}(\mathrm{OH})_{2}$ solution were applied to demonstrate the yield of $\mathrm{CO}_{2}$ in Fig. 5b and c. BTB solution was blue ( $\mathrm{I}, \mathrm{pH} \geq 8$ ), and turned into the blue-green (II) as the blank air carrier was injected because of the existence of $\mathrm{CO}_{2}$ in air. An obvious change happened and the color became green (III, $\mathrm{pH}=6-7$ ) 
(a)

(e)
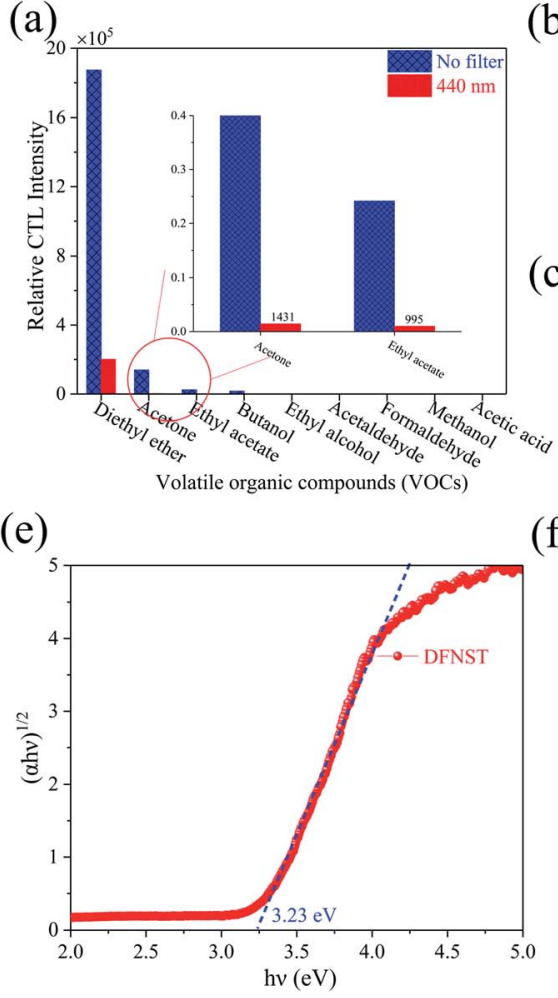

(b)

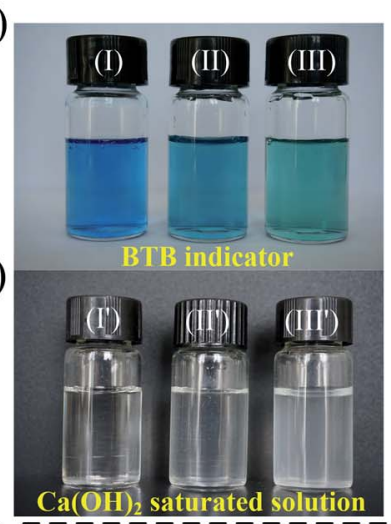

(f)

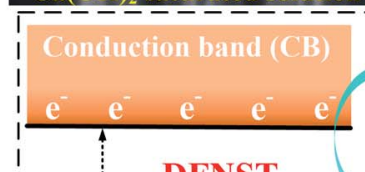

(d)

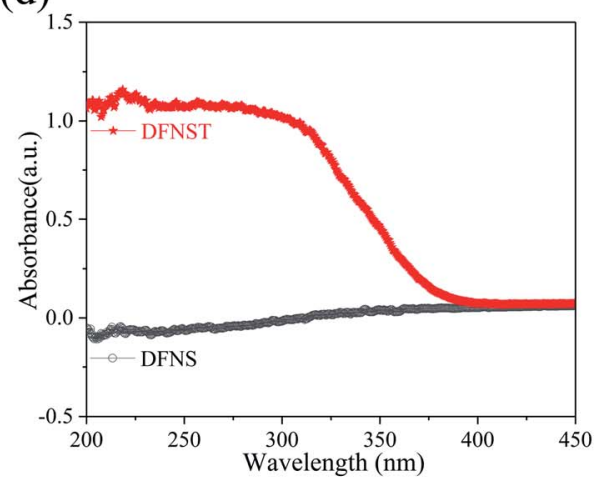

- $\left(\mathrm{CH}_{3} \mathrm{CH}_{2} \mathrm{OCH}_{2} \mathrm{CH}\right.$,

$\left(\mathbf{O}_{2}\right)$ diethyl ether)

DFNST

(anatase $\mathrm{TiO}_{2}$ )

$E_{\mathrm{g}}=3.23 \mathrm{eV}$

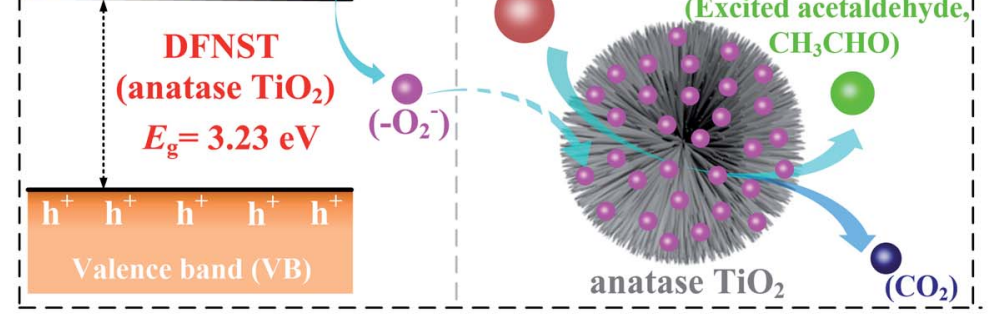

(Excited acetaldehyde,

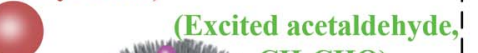

Fig. 5 The CTL spectra of different VOCs on DFNST-based sensor without or with the bandpass filter at $440 \mathrm{~nm}$ (a). The color change of BTB (b) and saturated $\mathrm{Ca}(\mathrm{OH})_{2}$ solutions (c) by injecting nothing (I), the blank air carrier (II), and the tail gas (III). UV-Vis-DRS spectra (d) and band gap $E_{\mathrm{g}}$ (e) of DFNST. The plausible CTL mechanism of diethyl ether on DFNST-based sensor ( $\mathrm{f}$ ).

above results imply that partial $\mathrm{Ti}-\mathrm{OH}$ groups heterogeneously condense with $\mathrm{Si}-\mathrm{OH}$ groups in DFNS for the formation of $\mathrm{Si}-$ $\mathrm{O}-\mathrm{Ti}$ and some other $\mathrm{Ti}-\mathrm{OH}$ groups condense with one another at the elevated temperature for the formation of $\mathrm{Ti}-\mathrm{O}-\mathrm{Ti}$, in good agreement with FT-IR and XPS results. Furthermore, UVVis-DRS was analyzed using Tauc plot to explore the band gap of DFNST (Fig. 5e). An indirect band gap exists in the hybrid material and the band gap value equals to $3.23 \mathrm{eV}$ that corresponds to crystalline $\mathrm{TiO}_{2}$ of anatase structure. ${ }^{23,40}$

Based on these results, the mechanism of diethyl ether on DFNST-based CTL sensor is proposed in Fig. $5 f$. Firstly, anatase $\mathrm{TiO}_{2}\left(E_{\mathrm{g}}=3.23 \mathrm{eV}\right)$ in DFNST can be motivated to generate hole $\left(\mathrm{h}^{+}\right)$and free electron $\left(\mathrm{e}^{-}\right)$at $280{ }^{\circ} \mathrm{C}$ (eqn (1)). Secondly, $\mathrm{O}_{2}$ adsorbed on the surfaces of DFNST nanochannels can be excited to generate oxygen activity species $\mathrm{O}_{2}{ }^{-}$with an electron from anatase $\mathrm{TiO}_{2}$ (eqn (2)). The as-produced $\mathrm{O}_{2}{ }^{-}$with the high capability of oxidization react with diethyl ether molecules that also adsorbed on the surface of DFNST nanochannels, giving rise to the excited-state intermediates of $\mathrm{CH}_{3} \mathrm{CHO}^{*}$ and $\mathrm{CO}_{2}^{*}$ (eqn (3)). Finally, the $\mathrm{CH}_{3} \mathrm{CHO}^{*}$ and $\mathrm{CO}_{2}^{*}$ return to ground-state of $\mathrm{CH}_{3} \mathrm{CHO}$ and $\mathrm{CO}_{2}$, accompanied with luminescence phenomenon (eqn (4) and (5)). The high response can be attributed to unique architectural texture of DFNST.

$$
\begin{aligned}
\operatorname{DFNST} \rightarrow & \operatorname{DFNST}\left(\mathrm{e}^{-}\right)+\operatorname{DFNST}\left(\mathrm{h}^{+}\right) \\
& \mathrm{O}_{2}^{-}+\mathrm{e}^{-} \rightarrow \mathrm{O}_{2}^{-}
\end{aligned}
$$

$$
\begin{aligned}
\left(\mathrm{C}_{2} \mathrm{H}_{5}\right)_{2} \mathrm{O}+\mathrm{O}_{2}^{-} & \rightarrow \mathrm{CH}_{3} \mathrm{CHO}^{*}+\mathrm{CO}_{2}^{*}+\mathrm{O}_{2} \\
\mathrm{CH}_{3} \mathrm{CHO}^{*} & \rightarrow \mathrm{CH}_{3} \mathrm{CHO}+\mathrm{e}^{-}+h v \\
\mathrm{CO}_{2}^{*} & \rightarrow \mathrm{CO}_{2}+\mathrm{e}^{-}+h v
\end{aligned}
$$

\section{Conclusions}

In summary, we have synthesized dendritic fibrous nano-silica \& titania (DFNST) hybrids as novel sensing materials to successfully fabricate DFNST-based cataluminescence sensor for ether detection. The as-prepared sensor possesses high selectivity by locating detection position with one $440 \mathrm{~nm}$ bandpass filter. Ether could be easily monitored in the range of $2.0-40 \mathrm{mM}$ with a detection limit of $1.55 \mathrm{mM}$ under the optimal conditions. The DFNST-based CTL sensor is stable and durable without damaging the morphology and activity of the sensing material after about 200 tests. It is expected that this novel sensing material and the corresponding CTL sensor will be significant for the detection of ether in actual application.

\section{Conflicts of interest}

There are no conflicts to declare. 


\section{Acknowledgements}

This work was supported by Natural Science Basic Research Plan in Shaanxi Province of China (No. 2019JQ-104), Doctoral Research Program of Yan'an University (No. YDBK2017-39), the Research Program of Yan'an University (No. YDQ2018-14), Shaanxi Province Training Program of Innovation and Entrepreneurship for Undergraduates (No. 201820042), Innovation Project of Graduate Education from Yan'an University (No. YCX201822).

\section{Notes and references}

1 H. Lin, M. Jang and K. S. Suslick, J. Am. Chem. Soc., 2011, 133, 16786-16789.

2 L. Zhang, S. Wang, Z. Yuan and C. Lu, Sens. Actuators, B, 2016, 230, 242-249.

3 H. Xu, Q. Li, L. Zhang, B. Zeng, D. Deng and Y. Lv, Anal. Chem., 2016, 88, 8137-8144.

4 L. Li, C. Wei, H. Song, Y. Yang, Y. Xue, D. Deng and Y. Lv, Anal. Chem., 2019, 91, 13158-13164.

5 H. Song, L. Zhang, C. He, Y. Qu, Y. Tian and Y. Lv, J. Mater. Chem., 2011, 21, 5972-5977.

6 X. Wang, N. Na, S. Zhang, Y. Wu and X. Zhang, J. Am. Chem. Soc., 2007, 129, 6062-6063.

7 J. Hu, L. Zhang, H. Song, J. Hu and Y. Lv, Anal. Chem., 2019, 91, 4860-4867.

8 G. Shi, B. Sun, Z. Jin, J. Liu and M. Li, Sens. Actuators, B, 2012, 171, 699-704.

9 Y. Zhen, H. Zhang, F. Fu and Y. Zhang, J. Mater. Sci.: Mater. Electron., 2019, 30, 3722-3728.

10 Y. Wang, X. Du, Z. Liu, S. Shi and H. Lv, J. Mater. Chem. A, 2019, 7, 5111-5152.

11 A. Maity, R. Belgamwar and V. Polshettiwar, Nat. Protoc., 2019, 14, 2177-2204.

12 A. Maity, S. Mujumdar and V. Polshettiwar, ACS Appl. Mater. Interfaces, 2018, 10, 23392-23398.

13 Y. Wang, Y. Wang, X. Li, J. Li, L. Su, X. Zhang and X. Du, ACS Sustainable Chem. Eng., 2018, 6, 14071-14081.

14 W. Byoun, S. Jung, N. M. Tran and H. Yoo, ChemistryOpen, 2018, 7, 349-355.

15 S. Li, X. Jiang, H. Sun, S. He, L. Zhang and L. Shao, J. Membr. Sci., 2019, 586, 185-191.

16 P. Yang, Q. Liu, J. Liu, R. Chen, R. Li, X. Bai and J. Wang, J. Hazard. Mater., 2019, 363, 248-257.

17 V. Polshettiwar, D. Cha, X. Zhang and M. B. Jean, Angew. Chem., Int. Ed., 2010, 49, 9652-9656.

18 V. Polshettiwar, J. Thivolle-Cazat, M. Taoufik, F. Stoffelbach and S. Norsic, Angew. Chem., Int. Ed., 2011, 50, 2747-2751.

19 A. Fihri, D. Cha, M. Bouhrara, N. Almana and V. Polshettiwar, ChemSusChem, 2012, 5, 85-89.
20 M. Bouhrara, C. Ranga, A. Fihri, R. R. Shaikh, P. Sarawade, A. H. Emwas, M. N. Hedhili and V. Polshettiwar, ACS Sustainable Chem. Eng., 2013, 1, 1192-1199.

21 X. Huang, Z. Tao, J. C. Praskavich, A. Goswami, J. F. AlSharab, T. Minko, V. Polshettiwar and T. Asefa, Langmuir, 2014, 30, 10886-10898.

22 Z. S. Qureshi, P. B. Sarawade, M. Albert, V. D'Elia, M. N. Hedhili and K. Köhler, ChemCatChem, 2015, 7, 635642.

23 R. Singh, R. Bapat, L. Qin, H. Feng and V. Polshettiwar, ACS Catal., 2016, 6, 2770-2784.

24 Z. S. Qureshi, P. B. Sarawade, I. Hussain, H. Zhu, H. AlJohani, D. H. Anjum, M. N. Hedhili, N. Maity, V. D'Elia and J. M. Basset, ChemCatChem, 2016, 8, 1671-1678.

25 B. Singh and V. Polshettiwar, J. Mater. Chem. A, 2016, 4, 7005-7019.

26 S. M. Saadati and S. M. Sadeghzadeh, Catal. Lett., 2018, 148, 1692-1702.

27 N. Bayal, R. Singh and V. Polshettiwar, ChemSusChem, 2017, 10, 2182-2191.

28 S. Kundu and V. Polshettiwar, ChemPhotoChem, 2018, 2, 796-800.

29 T. Qian, X. Yin, J. Li, H. E. Nian, H. Xu, Y. Deng and X. Wang, J. Mater. Sci. Technol., 2017, 33, 1314-1322.

30 Y. Wang, K. Hu, J. He and Y. Zhang, RSC Adv., 2019, 9, 24783-24790.

31 H. Yang, S. Li, X. Zhang, X. Wang and J. Ma, J. Mater. Chem. A, 2014, 2, 12060-12067.

32 S. M. Sadeghzadeh, Green Chem., 2015, 17, 3059-3066.

33 Z. Sun, H. Li, D. Guo, J. Sun, G. Cui, Y. Liu, Y. Tian and S. Yan, J. Mater. Chem. C, 2015, 3, 4713-4722.

34 A. Nyquist and R. O. Kagel, Infrared Spectra of Inorganic Compounds (3800-45 $\mathrm{cm}^{-1}$ ), Academic Press, New York, 1971.

35 Z. Li, B. Hou, Y. Xu, D. Wu and Y. Sun, J. Colloid Interface Sci., 2005, 288, 149-154.

36 J. Ren, Z. Li, S. Liu, Y. Xing and K. Xie, Catal. Lett., 2008, 124, 185-194.

37 C. X. C. Lin, C. Xu, Y. Yang, C. Lei, H. Zhang and C. Yu, New J. Chem., 2017, 41, 8754-8760.

38 D. Dastan, Appl. Phys. A: Mater. Sci. Process., 2017, 123, 699. 39 Y. Lian, W. Zhu, W. Yao, H. Yi, Z. Hu, T. Duan, W. Cheng, X. Wei and G. Hu, New J. Chem., 2017, 41, 4212-4219.

40 H. Tang, K. Prasad, R. Sanjines, P. E. Schmid and F. Levy, J. Appl. Phys., 1998, 75, 2042-2047.

41 H.-T. Lu, S.-L. Huang, I.-H. Tseng, Y.-K. Lin and M.-H. Tsai, J. Appl. Polym. Sci., 2013, 127, 145-153.

42 S. Wang, Y. Shi and X. Ma, Microporous Mesoporous Mater., 2012, 156, 22-28.

43 R. Singh, N. Bayal, A. Maity, D. J. Pradeep, J. Trébosc, P. K. Madhu, O. Lafon and V. Polshettiwar, ChemNanoMat, 2018, 4, 1-10.

44 K. S. W. Sing, Pure Appl. Chem., 1985, 57, 603-619. 